\title{
Responses to larval herbivory in the phenylpropanoid pathway of Ulmus minor are boosted by prior insect egg deposition
}

\author{
Johanna Schott ${ }^{1} \cdot$ Benjamin Fuchs ${ }^{1,3} \cdot$ Christoph Böttcher $^{2} \cdot$ Monika Hilker $^{1} \mathbb{C}$
}

Received: 18 August 2021 / Accepted: 23 November 2021 / Published online: 8 December 2021

(c) The Author(s) 2021

\begin{abstract}
Main conclusion Elms, which have received insect eggs as a 'warning' of larval herbivory, enhance their anti-herbivore defences by accumulating salicylic acid and amplifying phenylpropanoid-related transcriptional and metabolic responses to hatching larvae.
\end{abstract}

\begin{abstract}
Plant responses to insect eggs can result in intensified defences against hatching larvae. In annual plants, this eggmediated effect is known to be associated with changes in leaf phenylpropanoid levels. However, little is known about how trees-long-living, perennial plants-improve their egg-mediated, anti-herbivore defences. The role of phytohormones and the phenylpropanoid pathway in egg-primed anti-herbivore defences of a tree species has until now been left unexplored. Using targeted and untargeted metabolome analyses we studied how the phenylpropanoid pathway of Ulmus minor responds to egg-laying by the elm leaf beetle and subsequent larval feeding. We found that when compared to untreated leaves, kaempferol and quercetin concentrations increased in feeding-damaged leaves with prior egg deposition, but not in feedingdamaged leaves without eggs. PCR analyses revealed that prior insect egg deposition intensified feeding-induced expression of phenylalanine ammonia lyase (PAL), encoding the gateway enzyme of the phenylpropanoid pathway. Salicylic acid (SA) concentrations were higher in egg-treated, feeding-damaged leaves than in egg-free, feeding-damaged leaves, but SA levels did not increase in response to egg deposition alone-in contrast to observations made of Arabidopsis thaliana. Our results indicate that prior egg deposition induces a SA-mediated response in elms to feeding damage. Furthermore, egg deposition boosts phenylpropanoid biosynthesis in subsequently feeding-damaged leaves by enhanced $P A L$ expression, which results in the accumulation of phenylpropanoid derivatives. As such, the elm tree shows similar, yet distinct, responses to insect eggs and larval feeding as the annual model plant $A$. thaliana.
\end{abstract}

Keywords Flavonoids $\cdot$ Insect herbivory $\cdot$ Metabolomics $\cdot$ Plant defence $\cdot$ Priming $\cdot$ Salicylic acid

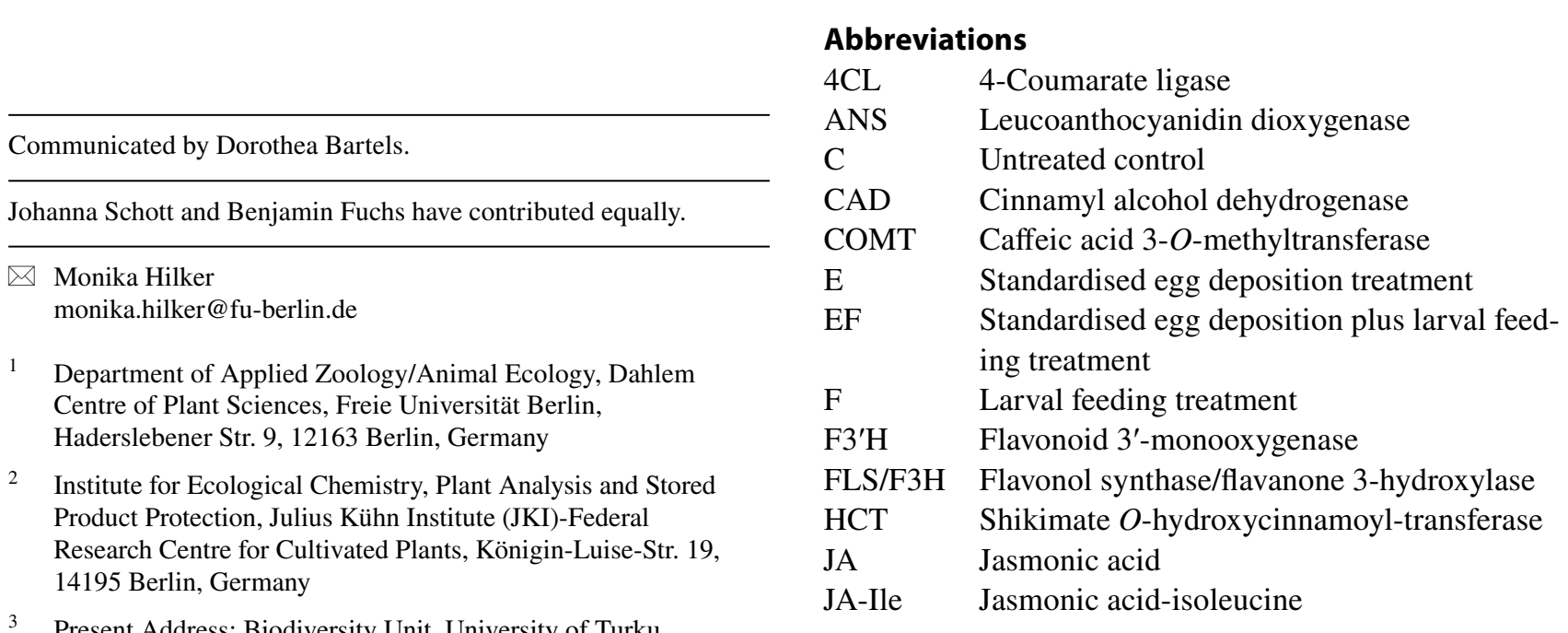


PAL Phenylalanine ammonia lyase

SA Salicylic acid

\section{Introduction}

Trees are a rich food source for many herbivorous insects. Herbivory may threaten forest ecosystems by massive defoliation and the transmission of serious diseases (Boyd et al. 2013). Trees have evolved a plethora of chemical and physical adaptations, which improve their survival in spite of frequent and severe stresses induced by insect infestations (Boeckler et al. 2011; Büchel et al. 2016; Caldwell et al. 2016). Stress-induced resistance in plants is an 'on-demand' strategy that invests resources in defences as they are needed (Wu and Baldwin 2010; Karban 2011; Stam et al. 2014; Turlings and Erb 2018). Several studies have shown that plants can even improve their inducible stress resistance by responding to environmental cues for impending stress; in this way, plants are able to 'get ready' and primed for mobilising their stress responses (Frost et al. 2008; Conrath et al. 2015; Mauch-Mani et al. 2017).

Environmental cues priming anti-herbivore defences include the first feeding damage prior to subsequent damage, leaf volatiles emitted by damaged neighbouring plants, and insect egg depositions that warn of impending larval feeding damage (Hilker et al. 2016, and references therein). Trees responding to these cues have been shown to improve their anti-herbivore defences against subsequently occurring insect herbivory (Haukioja 1991; Tscharntke et al. 2001; Frost et al. 2008; Beyaert et al. 2012; Austel et al. 2016; Li and Blande 2017).

However, the underlying mechanisms for priming inducible defences using herbivory-indicating cues have so far mainly been studied in annual plant species (Reymond 2013; Hilker and Fatouros 2016; Wilkinson et al. 2019). The feeding-induced phytohormonal and metabolic responses of several annual plant species that have been primed by insect egg deposition prior to larval herbivory differ from the feedinginduced responses of egg-free (non-primed) plants. These responses have been studied especially in Brassicaceae and Solanaceae. Phytohormonal analyses have revealed that egg-primed, feeding-induced brassicaceous plants show increased concentrations of salicylic acid (SA) (Bonnet et al. 2017; Lortzing et al. 2019). Egg-primed solanaceous plant species were found to respond to damage with higher concentrations of jasmonic acid (JA) (Kim et al. 2012) or enhanced transcription of a JA-responsive transcription factor (Bandoly et al. 2015). Egg deposition also affects the feeding-induced response of the phenylpropanoid pathway in both brassicaceous and solanaceous plants. Egg-primed, feeding-induced leaves of these plant taxa show higher levels of certain phenylpropanoid derivatives than non-primed ones after feeding damage (Bandoly et al. 2015; Lortzing et al. 2019) and enhanced expression of genes involved in the phenylpropanoid pathway (Geuss et al. 2018).

Previous studies indicate that phenylpropanoids also play a role in priming anti-herbivore defences in the field elm, Ulmus minor (Austel et al. 2016; Altmann et al. 2018). Elm responses to egg deposition by the elm leaf beetle Xanthogaleruca luteola enhance the tree's defences against larvae of this beetle species. Larvae feeding upon previously egg-laden leaves were shown to suffer higher mortality than larvae starting their development on egg-free leaves (Austel et al. 2016). Larvae that began their development on an eggtreated tree faced higher concentrations of a flavonoid glycoside, kaempferol-3-O-robinoside-7-O-rhamnoside, after an 8-day feeding period. Furthermore, application of high concentrations of this kaempferol glycoside onto (egg-free) elm leaves resulted in higher larval mortality (Austel et al. 2016). These results indicate the importance of this type of flavonoids for improved, egg-primed responses of elms to larval herbivory.

Flavonoids are late products of the phenylpropanoid pathway. The enzyme phenylalanine ammonia lyase (PAL) catalyses a crucial step at the beginning of the phenylpropanoid pathway, the deamination of phenylalanine. The resulting product, trans-cinnamic acid, is hydroxylated to 4-coumarate, which is further converted to 4-coumaryl-CoA; this step is catalysed by the enzyme 4-coumarate CoA ligase (4CL). From 4-coumaryl-CoA, the path branches in several directions. The reaction of shikimate $O$-hydroxycinnamoyltransferase (HCT) with 4-coumaryl-CoA as substrate continues to lignin-building units, which can be further modified by caffeic acid 3-O-methyltransferase (COMT) and cinnamyl alcohol dehydrogenase (CAD). In addition to the 'lignin branch', the phenylpropanoid pathway also deviates from 4-coumaryl-CoA to the biosynthesis of flavonoids. The flavonoid biosynthesis leading to kaempferol and quercetin derivatives involves, among other enzymes, F3H (flavanone 3-hydroxylase), FLS (flavonol synthase), and F3'H (flavonoid 3'-monooxygenase). Further downstream of the flavonoid branch, anthocyanin derivatives and catechins are produced; it is here that the enzyme leucoanthocyanidin dioxygenase (ANS) is involved (Vogt 2010; Tohge et al. 2017).

Several flavonoids, among them kaempferol and quercetin, glycosylated at different positions by various sugars, have been detected in elm leaves (Santamour 1972; BateSmith and Richens 1973; Martín et al. 2013). A previous comparative RNA-seq analysis of egg-treated and egg-free elm leaves after $6 \mathrm{~h}$ of feeding damage by elm leaf beetle larvae also pointed to a role of phenylpropanoids in egg-mediated priming of the elm's anti-herbivore defences (Altmann et al. 2018). The RNA-seq analysis identified enrichments in gene ontology (GO) terms related to cell wall organisation 
and phenylpropanoid metabolic and biosynthetic processes (Altmann et al. 2018).

The results of our earlier studies on elm responses to elm leaf beetle infestation prompted us to investigate further how egg-mediated priming of anti-herbivore defences in elm is processed. The aim of the present study was to elucidate how the phenylpropanoid pathway of egg-primed elm leaves responds to feeding damage by elm leaf beetle larvae. Furthermore, we aimed to determine which phytohormonal changes are involved in egg-priming of the elm's anti-herbivore defences. We addressed the following questions: (1) How does the beetle's egg deposition affect levels of phytohormones in elm leaves subsequently damaged by larval feeding? For this, we analysed levels of SA, JA, JAisoleucine (JA-Ile) and abscisic acid (ABA). (2) How do transcript levels of genes involved in the phenylpropanoid pathway change in egg-free and egg-primed leaves after the onset of larval feeding? To address this question, we studied transcript levels of the aforementioned (homologues of) genes encoding enzymes catalysing phenylpropanoid biosynthesis. (3) Do phenylpropanoid concentrations in eggprimed leaves increase after the onset of larval feeding?

With respect to questions (1) and (2), we took into account that changes of phytohormone levels and gene expression are known to vary rapidly following egg deposition and/or feeding (e.g., Altmann et al. 2018; Farmer et al. 2020). We analysed these parameters $6 \mathrm{~h}$ and $24 \mathrm{~h}$ after the onset of larval feeding upon egg-free or previously eggladen leaves. These time points were chosen since the elm RNA-seq analyses by Altmann et al. (2018) showed differential gene expression in egg-primed leaves early after larvae started feeding. Furthermore, we were interested in the spatial distribution of the phytohormonal and transcriptional responses to elm leaf beetle eggs and feeding. Therefore, we analysed both locally treated leaves and leaves adjacent to them. With respect to question (3), we focussed our analyses on locally treated leaves harvested $24 \mathrm{~h}$ after the onset of feeding because our analyses of phytohormone levels and gene expression revealed especially strong local effects at this time point.

\section{Materials and methods}

\section{Plants and insects}

Seed-grown, 1-year-old elm trees (Ulmus minor Miller) were purchased from Baumschule Appel (Waldsieversdorf, Germany) and potted in $5 \mathrm{~L}$ pots with potting soil Classic $\mathrm{T}$ (Einheitserde ${ }^{\circledR}$, Uetersen, Germany) mixed with 5\% vermiculite. The trees were kept in a greenhouse under long day conditions. In addition to daylight, trees were supplemented with light (EYE IWASAKI MT 400W/DL, Iwasaki electric
Co. Ltd., Tokyo, Japan) for $16 \mathrm{~h}$ a day. The 1-year-old trees used in our experiments were about $0.80-1.20 \mathrm{~m}$ tall and had grown up to ten branches deviating from the main axis. Each branch showed up to 18 fully developed leaves.

Elm leaf beetles (Xanthogaleruca luteola Müller) were collected from a natural population around Montpellier, France, where they occur in high densities. In the laboratory, the beetles were kept in microperforated polypropylene bags on twigs of potted elm trees at room temperature $\left(22-25^{\circ} \mathrm{C}\right.$, $16: 8 \mathrm{~h} \mathrm{light/dark}$ with $625-800 \mathrm{~lx}, 65-75 \%$ relative humidity). Inside these bags, beetles fed, mated and laid eggs upon leaves. Once several egg clutches were laid per twig, beetles were transferred to a new twig. Twigs with freshly hatched larvae were placed into plastic boxes covered with a gauze lid. The larvae were provided with fresh elm twigs three times per week until they pupated.

\section{General experimental design and conditions}

The experiments were conducted in our greenhouse between May and August. Elm trees were subjected to the following three treatments: (i) standardised egg deposition (E), (ii) larval feeding (F) upon egg-free leaves, and (iii) standardised egg deposition plus larval feeding (EF); this latter treatment was used to study how egg deposition affects the responses of leaves to subsequent larval feeding damage. To complete a full-factorial experimental design, we left elm trees untreated as controls (C).

One branch per tree was chosen for the treatments. All treatments were applied to four leaves per tree in the following manner: counting from the branching point, the first four leaves of a branch remained untreated and were not considered for sampling. They were followed by two treated, then two untreated, and then two treated leaves, ending with two untreated leaves. The sampled treated leaves are referred to as 'local' leaves, while the sampled untreated leaves are referred to as 'systemic' leaves (Fig. 1a).

Local and systemic leaves were harvested at consistent time points after treatment. Leaves subjected to the $\mathrm{F}$ and EF treatments were harvested $6 \mathrm{~h}$ or $24 \mathrm{~h}$ after the onset of larval feeding. Leaves from control trees and trees subjected to the $\mathrm{E}$ treatment were harvested at equivalent time points, i.e., after a 7-day E treatment period plus $6 \mathrm{~h}$ or $24 \mathrm{~h}$ (Fig. 1b). Harvesting E samples at these time points allowed us to determine whether an elm's response to the egg treatment was maintained during the natural egg incubation time, which lasts for 7 days, until larvae hatch from eggs. Immediately after harvesting, leaves from all treatments (C, E, F, EF) were stored in liquid nitrogen.

Each treatment was replicated ten times for each of the two harvest time points (i.e., there were 80 treated plants in total). Within each replicate, trees were treated on the same day and were of the same age and of comparable size. 


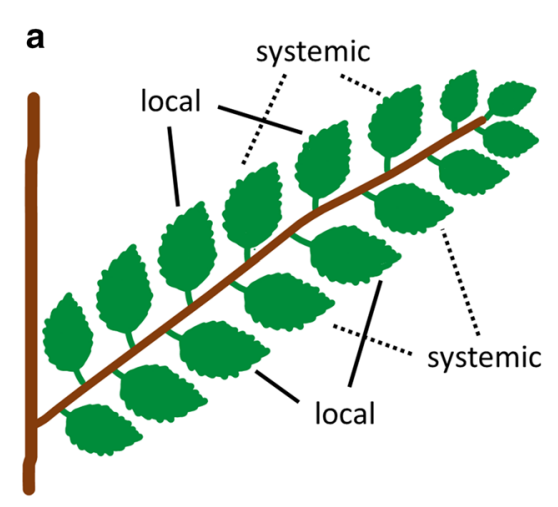

Fig. 1 Experimental design. a Position of locally treated Ulmus minor leaves (=local leaves) and adjacent leaves left untreated (=systemic leaves). We investigated local and systemic leaves. b Local leaves were exposed to an egg treatment and feeding damage by larvae of the elm leaf beetle Xanthogaleruca luteola. Treatments: $\mathrm{E}=$ egg treatment, $\mathrm{EF}=$ egg treatment and, 7 days later, larval feeding

Treatments were always applied between 10.00 a.m. and 11.00 a.m., to avoid possible variation in the parameters analysed due to time of day.

\section{Plant treatments: exposure to egg deposition and feeding}

To standardise the number, time, and site of egg depositions for the $\mathrm{E}$ and $\mathrm{EF}$ treatments, we mimicked natural egg deposition using the protocol described by Austel et al. (2016) and Altmann et al. (2018). Briefly, a small piece $(15 \mathrm{~mm} \times 1 \mathrm{~mm})$ of the abaxial leaf epidermis was gently removed with a scalpel, thus mimicking how a female elm leaf beetle removes leaf tissue with her mandibles prior to egg deposition at the oviposition site. This treatment was immediately followed by application of oviduct secretion from a freshly killed, gravid female beetle. This secretion envelops the eggs and is in immediate contact with the leaf. The oviductus communis of a female provided sufficient secretion for two standardised egg treatments. Previous studies have shown that treatment of leaves with oviduct secretion, as described here, elicits a plant response similar to that observed after natural egg deposition (Meiners and Hilker 2000; Austel et al. 2016); we refer to these as 'eggtreated' leaves.

For the feeding stimulus in $\mathrm{F}$ and EF treatments, we used neonate larvae from our rearing. Five newly hatched larvae were placed with a smooth brush onto each egg-treated leaf of an EF tree and onto the corresponding leaves of a $\mathrm{F}$ tree. This was carried out for the EF trees 7 days after treating the leaves with standardised egg deposition, and at the equivalent time for the $\mathrm{F}$ trees. The neonate larvae were restricted to feeding at the correct leaves by caging them in a plastic clip cage, which was gently fixed to the leaf. Leaves of $\mathrm{C}$ and

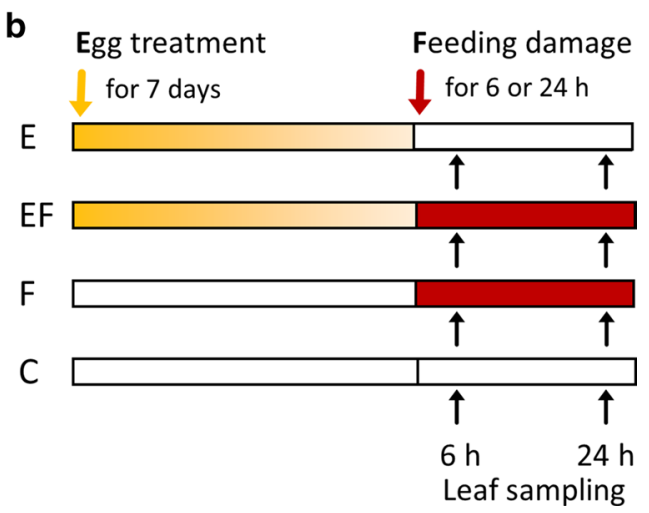

damage, $\mathrm{F}=$ feeding damage, $\mathrm{C}=$ untreated control. Yellow arrow: time point for egg treatment; red arrow: start of feeding damage by neonate larvae; duration of egg treatment: 7 days (i.e., natural egg incubation time for larvae to hatch); duration of larval feeding: $6 \mathrm{~h}$ or $24 \mathrm{~h}$. Black arrows: leaf material was sampled $6 \mathrm{~h}$ or $24 \mathrm{~h}$ after the onset of feeding and at equivalent time points in $\mathrm{C}$ and $\mathrm{E}$ leaves

E trees received (empty) clip cages at the same time points and positions on the branch.

\section{Determination of phytohormone concentrations}

To determine how elm leaf beetle egg deposition and larval feeding damage affected concentrations of the phytohormones SA, JA, JA-Ile, and ABA, phytohormone concentrations were determined $6 \mathrm{~h}$ and $24 \mathrm{~h}$ after onset of feeding in $\mathrm{F}$ and $\mathrm{EF}$ leaves and at the corresponding time points in $\mathrm{C}$ and $\mathrm{E}$ leaves. Both locally treated and systemic leaves were analysed. We used leaf powder aliquots of $80-100 \mathrm{mg}$ (fresh weight) each. The extraction procedure followed the protocol described by Wang et al. (2007). We added $1 \mathrm{~mL}$ ethyl acetate to each sample, together with an internal standard mix of the deuterated phytohormones D4-salicylic acid, D6-abscisic acid (both from OlChemIm Ltd., Olomouc, Czech Republic), D6-jasmonic acid and D6-jasmonyl-L-isoleucine (both from HPC Standards GmbH, Cunnersdorf, Germany). Samples were homogenised in a FastPrep instrument (MP Biomedicals, Solon, USA), followed by centrifugation. Afterwards, supernatants were transferred into new $2 \mathrm{~mL}$ tubes. Extraction was repeated using $1 \mathrm{~mL}$ ethyl acetate, and supernatants were combined, followed by evaporation to a honey-like viscosity (approx. $10 \mu \mathrm{L}$ volume) (Eppendorf Concentrator 5301, Eppendorf AG, Hamburg, Deutschland). Extracts were re-dissolved in $400 \mu \mathrm{L} 70 \%$ methanol with $0.1 \%$ formic acid and stored at $-20{ }^{\circ} \mathrm{C}$ until analysis. Phytohormone contents were analysed from $7 \mu \mathrm{L}$ solution injected into an UPLC-ESI-MS/MS on a Synapt G2-S HDMS (Waters ${ }^{\circledR}$, Milford, MA, USA). The detailed extraction protocol and UPLC conditions are described in Supplementary Information: protocols/phytohormone extraction and measurement. 


\section{qRT-PCR analysis}

To determine how elm leaf beetle egg deposition and larval feeding affect the expression levels of candidate elm genes involved in the phenylpropanoid pathway, we conducted qRT-PCR analyses using local and systemic leaves from the differently treated trees. Samples were harvested $6 \mathrm{~h}$ and $24 \mathrm{~h}$ after the onset of feeding from locally treated $\mathrm{F}$ and $\mathrm{EF}$ leaves and at the corresponding time points from $\mathrm{C}$ and $\mathrm{E}$ leaves. Samples from systemic $\mathrm{F}$ and EF leaves were harvested only after a $24 \mathrm{~h}$ feeding period and at the corresponding time from $\mathrm{C}$ and $\mathrm{E}$ leaves.

The plant material was ground under liquid nitrogen to a fine leaf powder. Total RNA from 50 to $60 \mathrm{mg}$ leaf powder (fresh weight) was extracted according to a chloroformbased protocol modified from Altmann et al. (2018) and Ikoma et al. (1996) (for further details, see Supplementary Information: protocols/RNA extraction). Any residual DNA was removed using DNase with the aid of DNA-free ${ }^{\mathrm{TM}} \mathrm{Kit}$ (Thermo Fisher Scientific, Waltham, MA, USA). RNA concentration and purity were determined spectrophotometrically, and RNA integrity was verified by gel electrophoresis on $1.8 \%$ agarose gels.

First-strand cDNA was synthesised from $1 \mu \mathrm{g}$ total RNA with the RevertAid ${ }^{\mathrm{TM}}$ RT Reverse Transcription Kit (Thermo Fisher Scientific). The protocol was modified to use oligo-dT and random hexamers to facilitate reverse transcription. Quantitative real time PCR (qRT-PCR) with $10 \mu \mathrm{L}$ reactions was performed in technical triplicates with $10 \mathrm{ng}$ cDNA and $5 \mu$ L Power $\mathrm{SYBR}^{\odot}$ Green Master Mix (Thermo Fisher Scientific) on a Stratagene Mx3005P Real-Time PCR System (Agilent Technologies Inc., Santa Clara, CA, USA) with a thermal profile of $1 \times\left(95^{\circ} \mathrm{C}\right.$ for $\left.10 \mathrm{~min}\right), 45 \times\left(95^{\circ} \mathrm{C}\right.$ for $20 \mathrm{~s}$ and $60{ }^{\circ} \mathrm{C}$ for $60 \mathrm{~s}$ ), followed by a melting curve analysis $\left(55-95^{\circ} \mathrm{C}\right)$.

Based on screening the U. minor RNA-seq data set provided by Altmann et al. (2018), we analysed sequences, which are homologues of genes known to be involved in the phenylpropanoid pathway. Primers were successfully designed using Clone Manager Suite 7 (Sci Ed Software, Westminster, CO, USA) for the sequences listed in Table S1. Each primer pair was tested for amplification efficiency and specificity by melting curve analysis and gel electrophoresis on a $2.7 \%$ agarose gel. The sequences analysed are putatively encoding the following enzymes: PAL, 4CL, HCT, COMT, CAD, FLS/F3H, F3'H and ANS. The $F L S / F 3 H$ sequence analysed here is based on the respective sequence published by Perdiguero et al. (2015), who conducted RNA-seq analyses of three $U$. minor genotypes. Perdiguero et al. (2015) annotated the $F L S / F 3 H$ sequence as flavonol synthase/flavanone-3-hydroxylase because it could not be determined unambiguously which of the two enzymes is encoded by this sequence. We decided to analyse transcript levels of the $F L S$ /
F3H sequence described by Perdiguero as (i) both enzymes catalyse biosynthesis steps between $p$-coumaroyl-CoA and kaempferol, and (ii) kaempferol derivatives are believed to play a role in elm defences against herbivory (Austel et al. 2016).

When quantifying transcript levels of the putative phenylpropanoid biosynthesis genes, we used sequences homologous to $S A N D$ family gene, $U B Q$ (polyubiquitin), and Splicing factor $3 B$ subunit 5 -like for normalisation. These reference genes showed treatment-independent, stable expression in a previous study, which sequenced and analysed the transcriptome of elm exposed to X. luteola egg deposition and larval feeding (Altmann et al. 2018). Primer sequences of the reference genes are included in Table S2. For quantification of transcripts, we calculated a reference gene index by determining the geometric mean of the expression levels of the three reference genes (Vandesompele et al. 2002). The relative expression levels of each sequence mentioned in Table $\mathrm{S} 1$ were calculated by relating the determined $2^{-\Delta \mathrm{Ct}}$ values to the reference index according to a modified protocol of Livak and Schmittgen (2001).

\section{Preparation of leaf extracts for metabolite analysis}

To determine changes in the levels of semipolar leaf metabolites in response to the study treatments, methanolic leaf extracts were prepared for HPLC-DAD and UHPLC-ESI-QTOFMS.

We prepared crude extracts from leaves subjected to the different treatments. Leaf metabolites were exclusively analysed in locally treated leaves harvested $24 \mathrm{~h}$ after the onset of larval feeding in $\mathrm{F}$ and $\mathrm{EF}$ leaves and in $\mathrm{C}$ and $\mathrm{E}$ leaves at the equivalent time. We focussed the metabolite analysis on these leaves because our earlier qRT-PCR and phytohormone analyses indicated treatment effects in these leaves in particular.

To obtain a crude leaf extract, an aliquot $(50 \mathrm{mg}$ ) of finely ground leaf powder was transferred under cooling with liquid nitrogen into a $2 \mathrm{~mL}$ Eppendorf tube. The tube was placed in a cooling rack (CoolRack, Corning Inc., Corning, NY, USA) in liquid nitrogen. We added $750 \mu \mathrm{L} 80 \%$ methanol to the powder in the tube; prior to this, the methanol had been cooled to $-80{ }^{\circ} \mathrm{C}$. The methanol added contained 4-chlorophenylalanine, umbelliferone, aspartame, phloridzin and biochanin A, each at $2 \mu \mathrm{M}$, as internal standards. The mixture was vortexed for $10 \mathrm{~s}$ and returned to the cooling rack for $5 \mathrm{~min}$. Vortexing for $10 \mathrm{~s}$ and cooling for $5 \mathrm{~min}$ were repeated for $30 \mathrm{~min}$, until samples were fully thawed. All subsequent steps were performed at room temperature. The vortexed sample was ultrasonicated for $15 \mathrm{~min}$. After centrifugation for $10 \mathrm{~min}$ at $18,213 \mathrm{~g}$ (Eppendorf $5437 \mathrm{R}$ centrifuge), $650 \mu \mathrm{L}$ of the resulting supernatant were transferred into a $2 \mathrm{~mL}$ reaction tube (Eppendorf). The remaining 
residue was extracted a second time with another $750 \mu \mathrm{L}$ $80 \%$ aqueous methanol by vortexing for $15 \mathrm{~min}$, followed by 15 min ultrasonication and 10 min centrifugation at $18,213 g$. Both supernatants were combined and provided $1300 \mu \mathrm{L}$ of leaf crude extract. The crude extracts were further processed for leaf metabolite analyses, as described below.

\section{Analysis of total kaempferol and quercetin}

HPLC-DAD was used to absolutely quantify the levels of two major flavonoids in the differently treated elm leaves. We focussed our analyses on kaempferol and its 3'-hydroxy derivative, quercetin, because a study by Austel et al. (2016) showed that a kaempferol derivative is detrimental to elm leaf beetle larvae. To determine the total concentration of the flavonol core structures, rather than the concentration of each of their various glycosides, we subjected the crude elm leaf extract to acidic hydrolysis according to a modified protocol from Hertog et al. (1992) and Mattila et al. (2000). A volume of $700 \mu \mathrm{L}$ leaf crude extract was transferred into a $2 \mathrm{~mL}$ centrifuge tube and evaporated to dryness under reduced pressure at $40{ }^{\circ} \mathrm{C}$ (Eppendorf Concentrator 5301). The remaining residue was suspended in $350 \mu \mathrm{L} 1.2 \mathrm{M} \mathrm{HCl}$, sonicated for $10 \mathrm{~min}$ and incubated for $1 \mathrm{~h}$ at $80{ }^{\circ} \mathrm{C}$ under constant shaking. After cooling to room temperature, $700 \mu \mathrm{L}$ ethyl acetate were added, and the mixture was vortex-mixed for $10 \mathrm{~min}$. After centrifugation for $10 \mathrm{~min}$ at $8000 \mathrm{~g}$ the organic phase was transferred into a $2 \mathrm{~mL}$ reaction tube. The remaining aqueous phase was extracted with another $700 \mu \mathrm{L}$ ethyl acetate. The combined organic extracts were evaporated to dryness under reduced pressure at $40{ }^{\circ} \mathrm{C}$. The resulting residue was dissolved in $200 \mu \mathrm{L} 70 \%$ methanol and subjected to HPLC-DAD (for details, see Supplementary Information: protocols/HPLC-DAD settings for analyses of flavonol aglycones). Quantification was carried out by external calibration curves with kaempferol and quercetin (Sigma Aldrich Corp., St. Louis, MO, USA).

\section{Phenylpropanoid metabolite profiling}

Ultra-high performance liquid chromatography/electrospray ionisation-quadrupole time-of-flight mass spectrometry (UHPLC/ESI-QTOFMS) was used to annotate and quantify levels of flavonol glycosides and several other phenylpropanoid derivatives in treated leaves relative to the levels in untreated control leaves.

For this quantitative analysis of metabolites, crude leaf extract $(200 \mu \mathrm{L})$ was transferred into a $2 \mathrm{~mL}$ centrifuge tube and evaporated to dryness under reduced pressure at $40{ }^{\circ} \mathrm{C}$. We added $200 \mu \mathrm{L} 50 \%$ methanol acidified with $0.1 \%(\mathrm{v} / \mathrm{v})$ formic acid to the remaining residue. The mixture was ultrasonicated for $10 \mathrm{~min}$ and centrifuged for $10 \mathrm{~min}$ at $18,213 \mathrm{~g}$. The resulting supernatant $(1 \mu \mathrm{L}$ of each type of leaf extract) was subjected to UHPLC/ ESI-QTOFMS analysis operated in negative ion mode. Prior to non-targeted analysis, a quality control was performed (for details, see Supplementary Information: protocols/UHPLC/ESI-QTOFMS settings for untargeted analyses and quality control). Raw data were analysed using the XCMS algorithm (non-targeted analysis) and MassHunter Qualitative and Quantitative Analysis software (Version B.07.00, Agilent Technologies Inc.) (targeted analysis). The parameter settings of feature detection, alignment, normalisation, and filtering are described in Supplementary Information: protocols/pre-processing of untargeted UHPLC/ESI-QTOFMS data of semipolar compounds.

The filtered peak area matrix (1395 features in all samples) was explored to identify quantitatively differential features. To this end, comparisons between the means of the $\log _{2}$-transformed peak areas of the following sample class pairs were performed using Welch's test, uncorrected for multiple testing: (i) $\mathrm{C}$ vs. $\mathrm{E}$, (ii) $\mathrm{C}$ vs. F, (iii) $\mathrm{C}$ vs. $\mathrm{EF}$, (iv) $\mathrm{F}$ vs. EF. With a significance threshold of $P<0.05$ and an absolute difference threshold $\mid \Delta$ mean $\mid \geq 1$, a total of 124 features were found, which showed different peak areas in at least one of the four pairwise comparisons.

For metabolite annotation, these 124 differential features were grouped by retention time and assigned to putative compound mass spectra based on the similarity of their elution profiles. After identifying pseudo-molecular, adduct and cluster ions within a putative compound mass spectrum, accurate mass collision-induced dissociation (CID) mass spectra were acquired by UHPLC/ ESI-QTOFMS in targeted MS/MS mode using scheduled precursor ion lists. CID spectra were compared with those in databases or were manually interpreted. Putative annotations were validated by comparison with chromatographic and mass spectral data of authentic compounds, wherever possible (for details, see Supplementary Information: protocols/compound annotation by UHPLC/ESI-QTOFMS in targeted MS/MS mode). For comprehensive annotation of flavonol glycosides, an all-ion fragmentation approach was used. For respective chromatograms see Fig. S1 ( $O$-glycosylated flavonols) and Fig. S2 (flavan-3-ols and derived dimeric and trimeric proanthocyanidins).

For final statistical evaluations and visualisation of quantitative differences, all annotated metabolites detected by UHPLC/ESI-QTOFMS were quantified again via a manual process using MassHunter Quantitative Analysis software; we listed $\mathrm{m} / \mathrm{z}$ and the retention times of respective quantifier ions in Table S3. The results of this quantification were set relative to the quantities detected in untreated control leaves and were normalised to leaf fresh weight. 


\section{Statistics}

All statistical analyses were performed with the software "R", version 4.0.2 (R Core Team 2020), using the packages car (version 3.0-9, Fox and Weisberg 2018), ggplot2 (version 3.3.2, Wickham 2016), plyr (version 1.8.6, Wickham 2011), and multcomp (version 1.4-13, Hothorn et al. 2008). For untargeted metabolome analysis, we used XCMS (Smith et al. 2006), and for the heatmap we used ComplexHeatmap (version 2.4.3, Gu et al. 2016, http://bioconductor.org/biocL ite.R).

Data were checked for normal distribution using Q-Q plots. Homogeneity of variances was tested with Levene's test. Data not normally distributed were $\log _{2}$-transformed and analysed again. Extreme outliers (values above $\mathrm{Q} 3+3 \times \mathrm{IQR}$, or below $\mathrm{Q} 1-3 \times \mathrm{IQR}$ ) were not included in the statistical evaluation of data obtained from analyses of concentrations of phytohormones, transcript levels, or levels of hydrolysed metabolites. Normally distributed data were evaluated by one-way ANOVA and post-hoc general linear hypothesis test (glht) with Tukey contrasts. Data not normally distributed even after $\log _{2}$-transformation were analysed using the Kruskal-Wallis test and post-hoc pairwise comparisons using Benjamini-Hochberg-corrected Wilcoxon rank-sum tests.

\section{Results}

\section{Effects of egg deposition and larval feeding on elm phytohormone levels}

Levels of SA were significantly higher in locally treated EF leaves than $\mathrm{F}$ leaves after a $24 \mathrm{~h}$ feeding period. This eggmediated effect on the SA concentration in feeding-damaged elm leaves was not detectable after a $6 \mathrm{~h}$ feeding period. Neither egg treatment nor feeding damage per se affected SA levels, regardless of the time point of sampling. No treatment effects on SA levels were detected in systemic leaves (Fig. 2a; Tables S4, S5).

Levels of JA and JA-Ile were, as expected, significantly higher in both locally treated $\mathrm{F}$ and EF leaves. This feeding-induced effect was detectable after both a $6 \mathrm{~h}$ and $24 \mathrm{~h}$ larval feeding period (Fig. 2b, c). Prior egg deposition did not enhance the feeding-induced JA levels in locally treated leaves. In systemic F and EF leaves, concentrations of JA and JA-Ile increased in response to feeding but remained below $5 \mathrm{ng} \mathrm{g}^{-1}$ fresh weight in all treatments (Tables $\mathrm{S} 4$, S5).

Levels of ABA changed neither in response to the egg treatment, to larval feeding, nor to a combination of both treatments (Tables S4, S5). This lack of treatment effects was observed in local and systemic leaves both $6 \mathrm{~h}$ and $24 \mathrm{~h}$ after the onset of feeding damage.

In summary, concentrations of SA were only enhanced in local, previously egg-treated leaves after $24 \mathrm{~h}$ of feeding, while larval feeding increased JA and JA-Ile concentrations after both $6 \mathrm{~h}$ and $24 \mathrm{~h}$ of feeding in locally treated leaves.

\section{Effects of egg deposition and larval feeding on elm genes involved in the phenylpropanoid pathway}

The effects of egg deposition on expression of genes involved in the phenylpropanoid pathway were detectable only for $P A L$. Prior elm leaf beetle egg deposition affected transcript levels of $P A L$ in locally treated elm leaves exposed to $24 \mathrm{~h}$ of larval feeding. These $E F$ leaves showed significantly higher transcript levels than $\mathrm{F}$ leaves (Fig. 2d). This egg-mediated enhancer effect on $P A L$ expression in local, feeding-induced elm leaves was not detectable after a $6 \mathrm{~h}$ feeding period (Fig. $2 \mathrm{~d}$ ). In the absence of larval feeding damage, $P A L$ expression levels were not enhanced in locally treated $\mathrm{E}$ leaves at the $6 \mathrm{~h}$ or $24 \mathrm{~h}$ leaf sampling time points. In local leaves, whether $\mathrm{E}$ or EF leaves, expression of none of the other tested candidate genes- $4 C L$, $H C T, C A D, C O M T, F L S / F 3 H, F 3^{\prime} H, A N S$ - was affected by elm leaf beetle egg deposition (Table S6). When considering gene expression in systemic $\mathrm{E}$ and $\mathrm{EF}$ leaves after a $24 \mathrm{~h}$ feeding period, no effects of prior egg deposition were detected on transcript levels of the genes tested (Table S7).

Larval feeding induced expression of $P A L, H C T$ and $A N S$ in locally treated leaves with and without prior egg deposition. While $P A L$ and $A N S$ showed enhanced transcript levels both after $6 \mathrm{~h}$ and $24 \mathrm{~h}$ of larval feeding in locally treated leaves, $H C T$ expression was significantly higher only after a $6 \mathrm{~h}$ feeding period, and only when compared to egg-treated E leaves without feeding damage (Fig. 2d-f). In local leaves, expression of none of the other tested candidate genes$4 C L, H C T, C A D, C O M T, F L S / F 3 H, F 3^{\prime} H$-was affected by $24 \mathrm{~h}$ of larval feeding (Table S6). When considering systemic effects of larval feeding, $P A L$ and $A N S$ transcript levels were significantly higher after a $24 \mathrm{~h}$ larval feeding period, regardless of whether the leaves received an egg treatment beforehand (Table S7). Larval feeding for $24 \mathrm{~h}$ did not affect expression levels of any of the other tested candidate genes in systemic leaves (Table S7).

As such, insect egg deposition amplifies the feedinginduced expression of a homologue to phenylalanine ammonia lyase $(P A L)$, a gene encoding an enzyme at the entrance of the phenylpropanoid pathway, in elm leaves. This eggmediated enhancer effect was only detectable in locally treated leaves after a $24 \mathrm{~h}$ larval feeding period. 
a

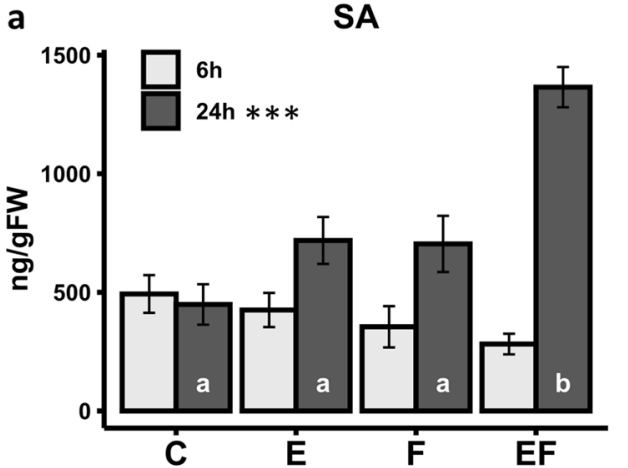

b

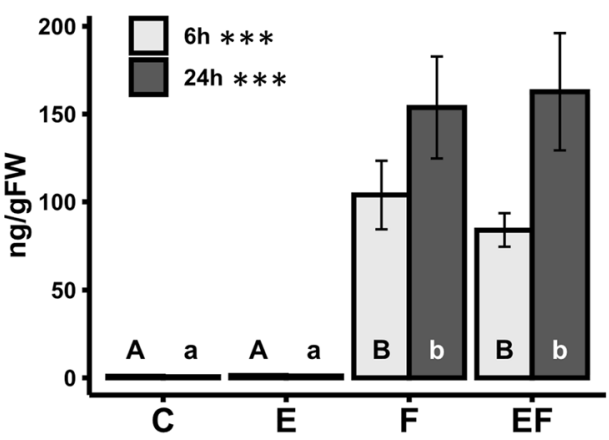

C

JA-Ile

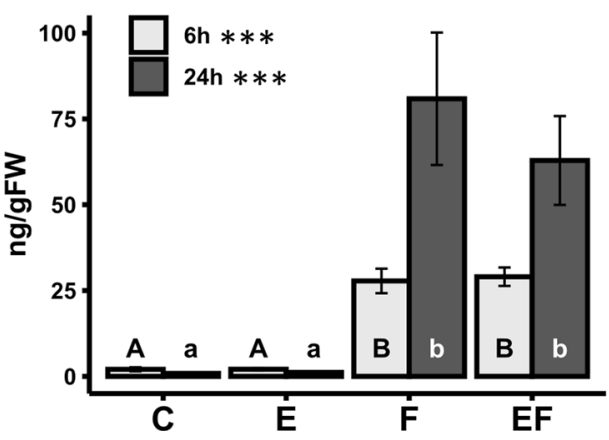

Fig. 2 Effects of elm leaf beetle egg deposition and larval feeding on phytohormone concentrations and expression of Ulmus minor genes involved in phenylpropanoid biosynthesis. Concentrations of a salicylic acid (SA), b jasmonic acid (JA), and $\mathbf{c}$ jasmonic acid-isoleucine (JA-Ile), as well as expression of $\mathbf{d} P A L$ (phenylalanine ammonia lyase) e ANS (leucoanthocyanidin dioxygenase), f HCT (shikimate O-hydroxycinnamoyl-transferase) were measured in locally treated leaves after $6 \mathrm{~h}$ (grey bars) or $24 \mathrm{~h}$ (black bars) of larval feeding, and at equivalent time points for treatments without larval feeding. $\mathrm{C}=$ untreated control leaves, $\mathrm{E}=$ egg-treated leaves, $\mathrm{F}=$ feeding-damaged leaves, $\mathrm{EF}=$ egg-treated, feeding-damaged leaves. a-c Bars represent means \pm SE of $n=9-10$ samples. One-way ANOVA was performed separately for log-transformed data from 6 and $24 \mathrm{~h}$ samples. In cases of a significant result $(* P<0.05, * * P<0.01, * * * P<0.001)$,

\section{Effects of egg deposition and larval feeding on metabolites of the phenylpropanoid pathway}

HPLC-DAD analysis of flavonol aglycones in locally treated leaves revealed that levels of kaempferol and quercetin were significantly higher in $24 \mathrm{~h}$ feeding-damaged elm leaves with
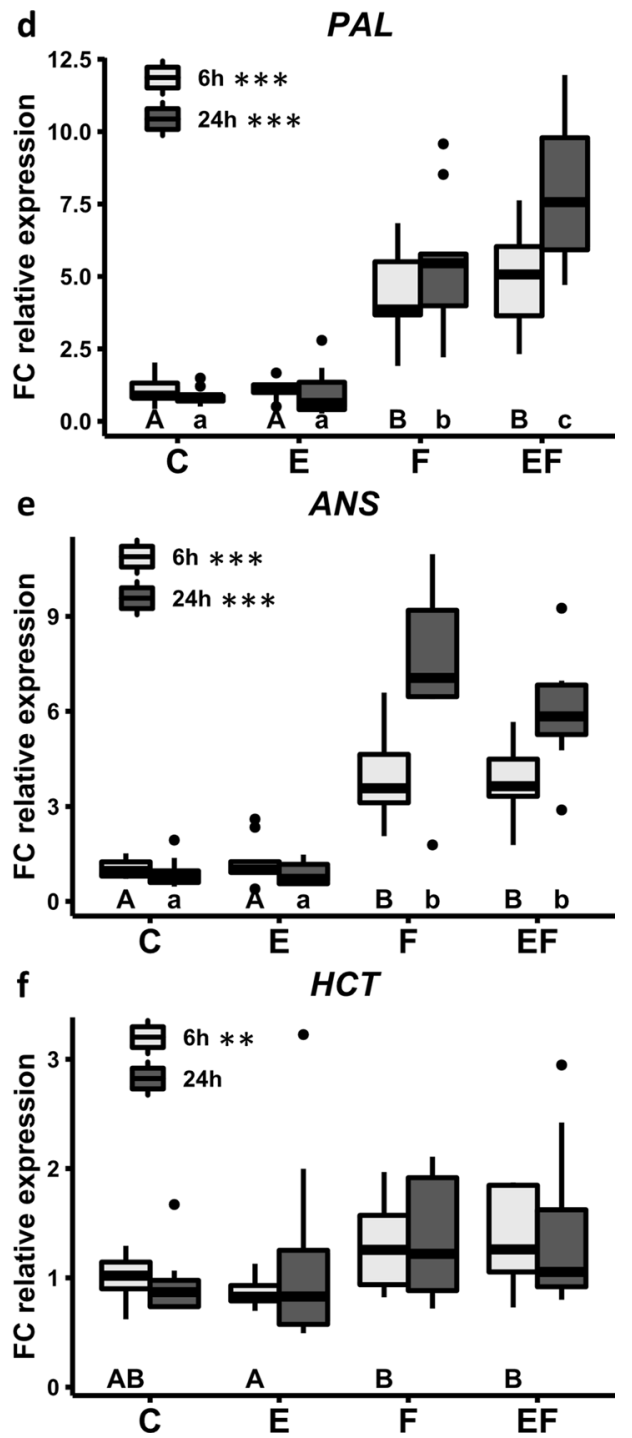

Tukey test with single-step adjusted $P$ values was carried out as a post-hoc test. d-f Boxplots indicate median, first and third quartiles of $n=8-10$ samples; FC $=$ fold change relative to control. Dots show outliers beyond 1.5-times the interquartile range, which is represented by whiskers. Kruskal-Wallis tests were separately performed for $6 \mathrm{~h}$ and $24 \mathrm{~h}$ samples. In case of a significant Kruskal-Wallis test result $(* P<0.05, * * P<0.01, * * * P<0.001)$, the Wilcoxon rank-sum test with Benjamini-Hochberg correction was used to test for differences between treatments. a-f In the event of significant results from Kruskal-Wallis test or ANOVA, significant differences between treatments as determined by the aforementioned post-hoc tests $(P<0.05)$ are indicated by different capital letters ( $6 \mathrm{~h}$ samples) and lowercase letters ( $24 \mathrm{~h}$ samples)

prior egg deposition than in untreated control leaves (Fig. 3a, b; Table S8). Neither egg deposition nor feeding damage alone induced a significant increase in concentrations of these compounds. The quercetin concentrations of $\mathrm{F}$ and $\mathrm{EF}$ leaves differed significantly. The kaempferol concentration 

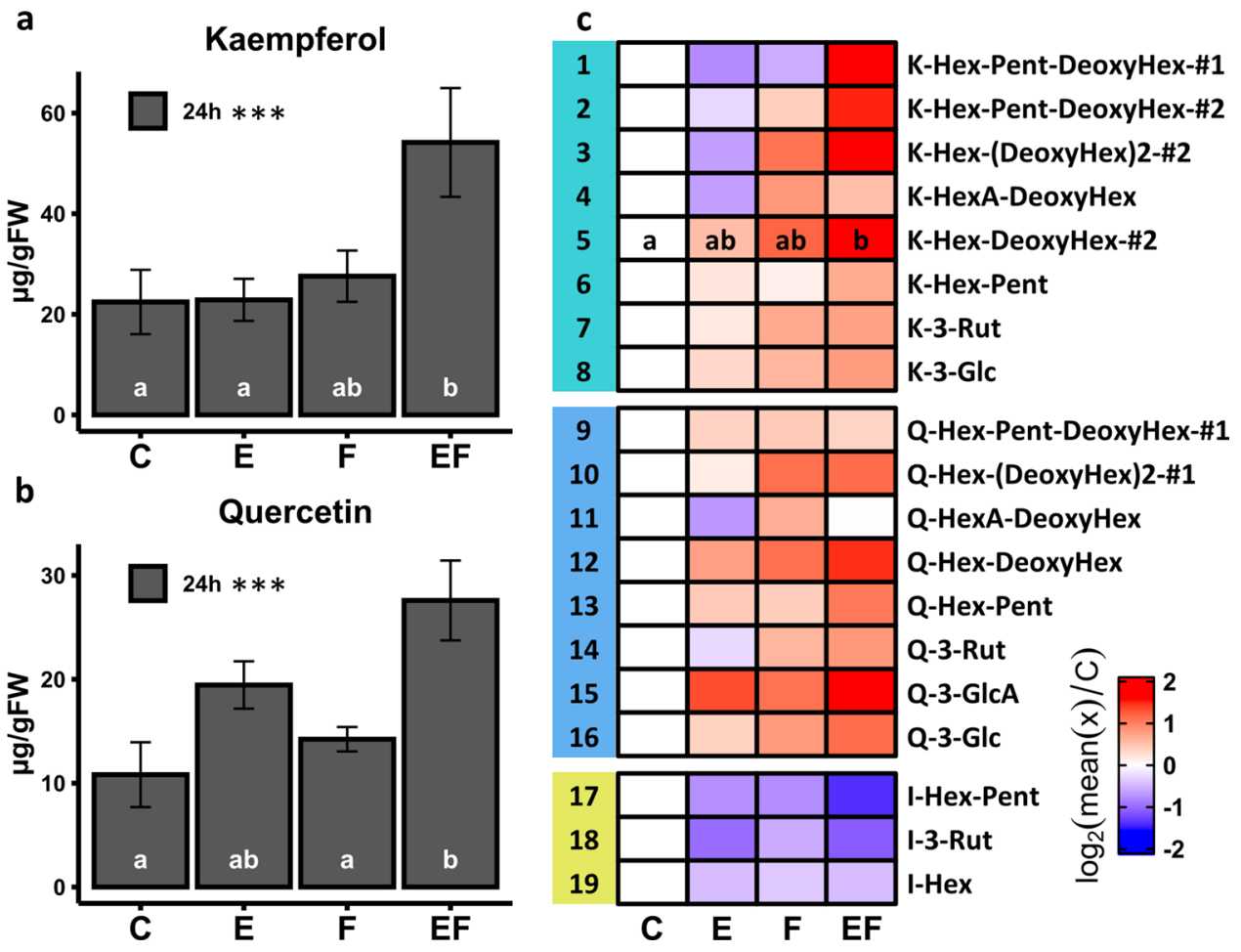

Fig. 3 Impact of elm leaf beetle egg deposition and larval feeding on Ulmus minor flavonoid content. Total concentrations of kaempferol (a) and quercetin (b) as analysed by HPLC-DAD of acid-hydrolysed methanolic leaf extracts. Heatmap in c shows $\log _{2}$ fold change of metabolite levels of flavonol glycosides detected in methanolic leaf extracts by UHPLC/ESI-QTOFMS. Relative peak areas were standardised to leaf fresh weight. $\log _{2}$ fold change relative to control was calculated by $\log _{2}$ of the ratio of the mean peak area per metabolite in a treated leaf relative to the mean of the respective metabolite peak area in the control. Numbers in $\mathbf{c}$ refer to compound numbers men-

was almost doubled in EF leaves compared to $\mathrm{F}$ leaves; this difference was marginally significant $(P=0.06)$.

Using UHPLC/ESI-QTOFMS, we detected a total of 19 flavonol glycosides in methanolic extracts of locally treated elm leaves. We quantified eight kaempferol derivatives, eight quercetin derivatives and three isorhamnetin derivatives (Fig. 3c; Tables S3, S9). Overall, the variability of biological samples was relatively high. We recorded a significant increase in concentration of only one kaempferol glycoside when comparing EF leaves to untreated controls (Fig. 3c; compound \#5). The concentrations of compounds \#1-3 showed a similar pattern across the differently treated leaves, with the highest concentrations in EF leaves. Concentrations of five quercetin derivatives showed a similar pattern across treatments to that of the quercetin aglycone (compare Fig. 3b, c), with the highest concentrations in EF treated leaves (Fig. 3c; compounds \#12-16). Compounds \#4 and 11 were the only compounds with lower concentrations in EF leaves than in $\mathrm{F}$ leaves. Concentrations of all identified isorhamnetin derivatives slightly decreased in E, tioned in the text; kaempferol (1-8), quercetin (9-16) and isorhamnetin derivatives (17-19). $\mathrm{C}=$ untreated control leaves, $\mathrm{E}=$ locally egg-treated leaves, $\mathrm{F}=$ locally feeding-damaged leaves, $24 \mathrm{~h}$ feeding period, $\mathrm{EF}=$ locally egg-treated, feeding-damaged leaves, $24 \mathrm{~h}$ feeding period. Statistics in a-c ANOVA, in case of significance $(P<0.05)$ followed by Tukey test as post-hoc test with single-step adjusted $P$ values. In a and $\mathbf{b} * * *$ ANOVA $P<0.001$. In $\mathbf{a}-\mathbf{c}$ different letters indicate significant differences between treatments (Tukey test $P<0.05) ; n=9-10$

$\mathrm{F}$ and EF leaves as compared to untreated controls (Fig. 3c; compounds \#17-19).

To elucidate how egg deposition and larval feeding might affect phenylpropanoid compounds other than the flavonol glycosides, we subjected the LC/MS profiles of methanolic elm leaf extracts to a non-targeted analysis. We were able to detect 124 features, which differed in their peak area in at least one of the pairwise comparisons of untreated controls with $\mathrm{E}, \mathrm{F}$ and $\mathrm{EF}$ leaves and of the comparison between $\mathrm{F}$ and EF leaves. Further analysis of these features allowed us to assign them to 20 compounds, among which we could tentatively identify 12 metabolites. Of these 12,11 could be further specified as shikimate/phenylpropanoid derivatives (compounds \#20-30; Fig. 4a, b; Tables S3, S10), and the other as suberic acid (compound \#31, Table S3). No reliable compound classification was possible for the remaining eight metabolites (compounds \#32-39, Table S3). Coumaroyl-quinate (compound \#26) was the only tentatively identified phenylpropanoid compound to appear at a significantly increased concentration in EF leaves compared to 
a

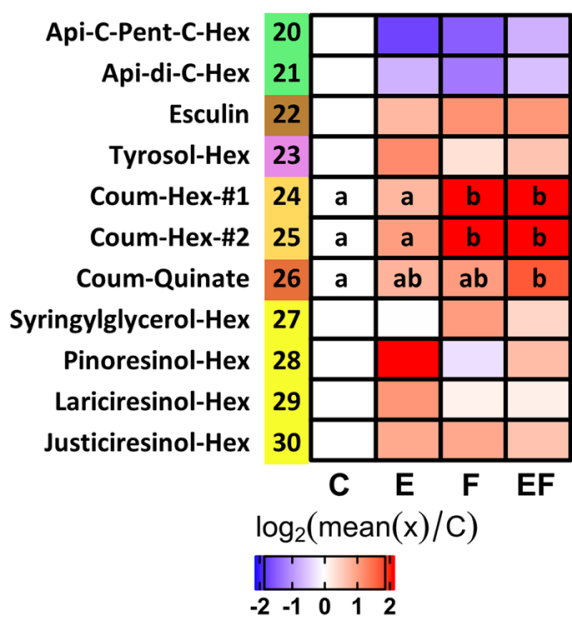

b
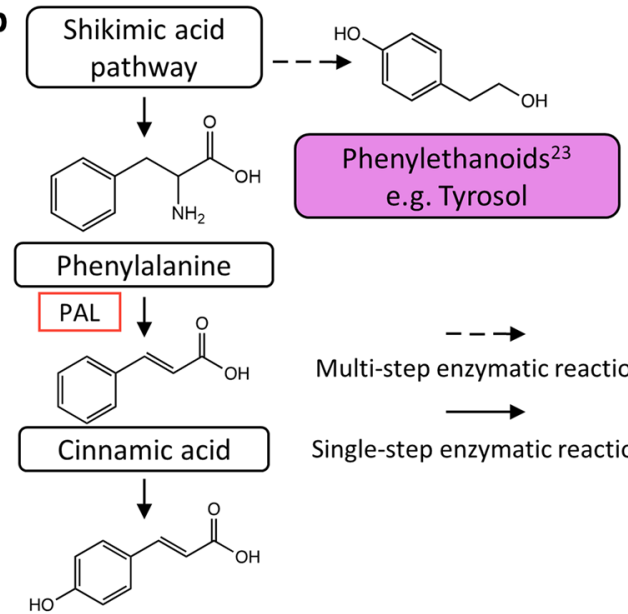

Multi-step enzymatic reactions

Single-step enzymatic reactions

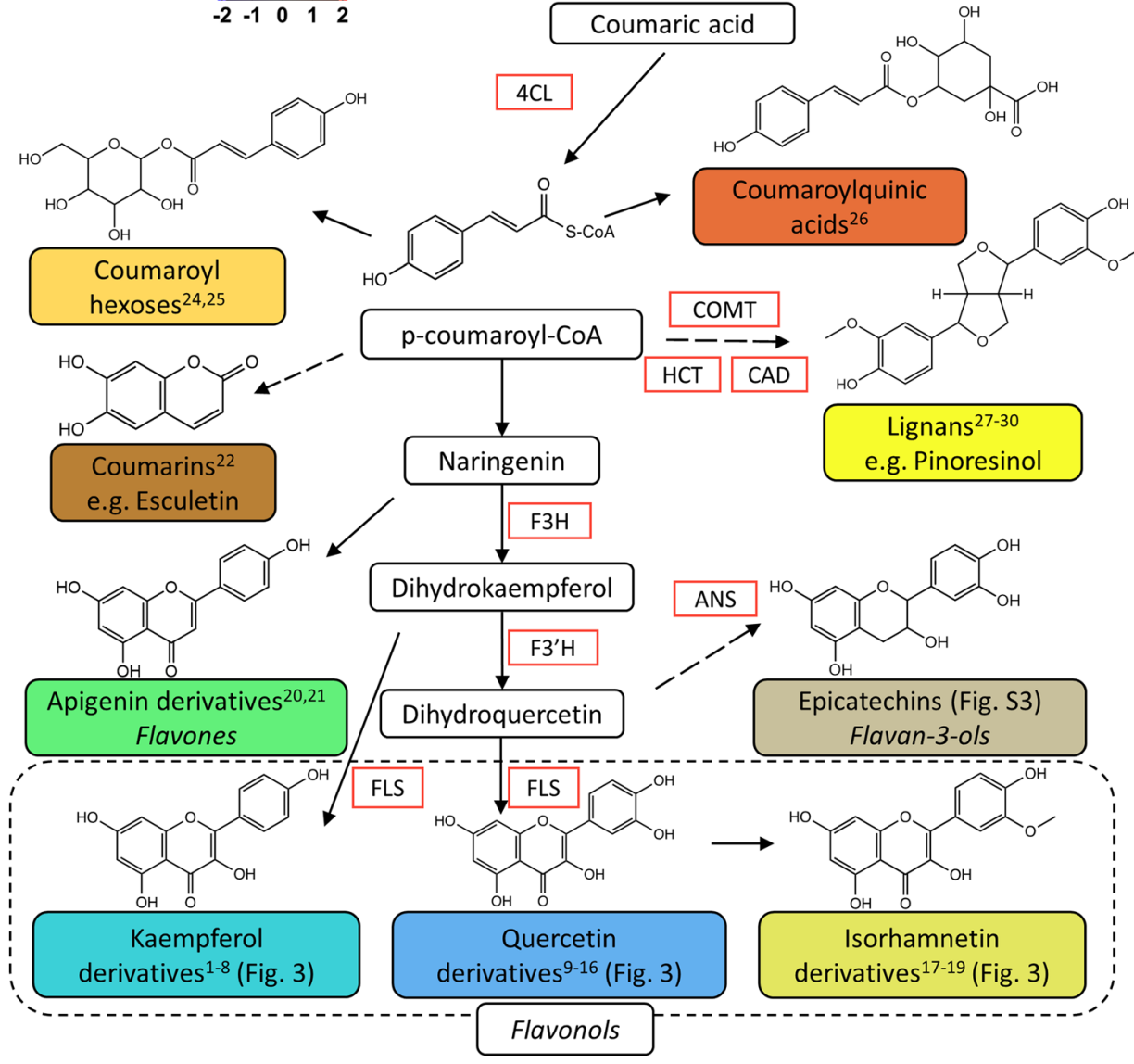

Fig. 4 Impact of elm leaf beetle egg deposition and larval feeding on putatively identified Ulmus minor phenylpropanoid metabolites. UHPLC/ESI-QTOFMS-analysis of semipolar compounds present in a methanolic elm leaf extract. a Heatmap shows $\log _{2}$ fold change of metabolite levels in a treated leaf relative to an untreated control leaf. Relative peak areas were standardised to leaf fresh weight. $\log _{2}$ fold change relative to control was calculated by $\log _{2}$ of the ratio of the mean peak area per metabolite in a treated leaf relative to the mean of the peak area of the respective metabolite in the control. Colouring and numbers next to substance names code for pathway affiliation (see b). Treated leaves are labelled as follows: $\mathrm{E}=$ locally eggtreated leaves; $\mathrm{F}$ =locally feeding-damaged leaves, $24 \mathrm{~h}$ feeding period; $\mathrm{EF}$ = locally egg-treated, feeding-damaged leaves, $24 \mathrm{~h}$ feeding period; $\mathrm{C}=$ untreated control leaves. Statistics: ANOVA, in case of significance $(P<0.05)$ followed by Tukey test as post-hoc test with single-step adjusted $P$ values. Different letters indicate significant differences between treatments $(P<0.05) ; n=9-10$. Compounds referred to twice are isomeric structures with the same molecular weight but differing retention times. b Simplified visualisation of the phenylpropanoid pathway. Colours and indexed numbers represent the compound affiliation of respective compounds in the heatmap shown in a. Enzymes catalysing selected biosynthetic steps are indicated; PAL phenylalanine ammonia lyase, 4CL 4-coumarate ligase, HCT shikimate $O$-hydroxycinnamoyl-transferase, CAD cinnamyl alcohol dehydrogenase, COMT caffeic acid 3-O-methyltransferase, F3H flavanone 3-hydroxylase, F3'H flavonoid 3'-monooxygenase, FLS flavonol synthase, ANS leucoanthocyanidin dioxygenase 
C leaves. Levels of two isomeric coumaroyl-hexoses were increased by feeding in both $\mathrm{F}$ and EF leaves (compounds $\# 24,25)$. Similar to isorhamnetin derivatives, levels of two apigenin derivatives decreased slightly, but not significantly, in response to all treatments when compared to controls (compounds \#20, 21).

In addition to the flavonol glycosides shown in Fig. 3, we detected the flavan-3-ols catechin, epicatechin and their dimers and trimers in the methanolic elm leaf extract. Of the seven substances identified, only epicatechin showed a tentative increase in egg-treated E leaves and a tentative decrease in EF leaves as compared to untreated controls; however, none of the comparisons revealed any significant differences (Fig. S3; Tables S3, S9).

Taken together, the metabolite analyses showed that feeding damage by neonate elm leaf beetle larvae for $24 \mathrm{~h}$ upon egg-free leaves did not result in enhanced concentrations of phenylpropanoid derivatives, except for coumaric acid glycosides. Likewise, egg deposition per se did not lead to significant changes in phenylpropanoid concentrations. However, elm leaves with prior egg deposition accumulated higher concentrations of the flavonoids kaempferol and quercetin in response to larval feeding damage. These two flavonols were detected in several glycosylated forms.

\section{Discussion}

Our study shows that insect egg deposition on a deciduous tree significantly shapes that tree's phytohormonal and metabolite response to larvae hatching from the eggs. The effects of elm leaf beetle egg deposition on feeding-damaged elm leaves are manifested in enhanced levels of the phytohormone SA and of some phenylpropanoid derivatives after $24 \mathrm{~h}$ feeding by neonate larvae. Expression levels of $P A L$, which encodes the "gateway" enzyme (Zhang and Liu 2015) at the entrance of the phenylpropanoid pathway, were increased after feeding in previously egg-laden leaves to a greater extent than in egg-free, feeding-damaged leaves. However, in feeding-damaged leaves, expression levels of other genes involved in phenylpropanoid biosynthesis were not affected by prior egg deposition.

\section{Effects of egg deposition and larval feeding on elm phytohormone levels}

In elm, the induction of JA and its bioactive form, JA-Ile, by larval feeding for $6 \mathrm{~h}$ and $24 \mathrm{~h}$ was independent of prior egg deposition. In another perennial plant species, the bittersweet nightshade Solanum dulcamara, increases of JA and JA-Ile levels after a $24 \mathrm{~h}$ larval feeding period were also independent of prior egg deposition (Geuss et al. 2018). In contrast, JA and JA-Ile levels in other species with shorter longevity were affected by prior egg deposition. However, concentrations of these phytohormones were measured very early after the onset of damage. For instance, higher JA levels were detected in egg-treated tomato plants $30 \mathrm{~min}$ and 60 min after wounding (Kim et al. 2012). In Arabodpsis thaliana, Valsamakis et al. (2020) found enhanced JA-Ile levels in egg-treated leaves after a $3 \mathrm{~h}$ larval feeding period when compared to egg-free, feeding-damaged leaves, but not after a $12 \mathrm{~h}$ feeding period. Future studies will need to investigate whether previously egg-laden elm leaves show enhanced JA levels very early on after the onset of larval feeding.

Levels of SA were significantly enhanced in previously egg-treated elm leaves after a larval feeding period of $24 \mathrm{~h}$. Similarly, significantly enhanced SA levels were detected in A. thaliana when laden with eggs by the butterfly Pieris brassicae and subsequently damaged by its hatching larvae for $24 \mathrm{~h}$ (Lortzing et al. 2019; Valsamakis et al. 2020). In contrast, moth egg depositions upon the annual species Nicotiana attenuata and the perennial S. dulcamara did not affect SA levels in subsequently larval feeding-damaged leaves (Drok et al. 2018). Thus, the SA response of plants to egg deposition and subsequent larval feeding damage varies according to the interacting plant and insect species. In the species studied to date, there is no apparent relationship between plant longevity and the increased SA content in egg-laden, feeding-damaged leaves.

Enhanced SA levels in egg-treated, feeding-damaged elm leaves are accompanied by enhanced transcript levels of PAL. Enhanced activity of PAL might contribute to the higher levels of SA in EF leaves, since this phytohormone might be produced via a PAL-dependent pathway in elm. While numerous studies indicate that SA in A. thaliana is predominantly produced via the isochorismate (IC) pathway (Dempsey et al. 2011; Rekhter et al. 2019), the PALdependent pathway is an additional biosynthetic route to SA. Along this PAL-dependent pathway, phenylalanine is converted into trans-cinnamic acid, which may then be further processed via different steps to ortho-coumaric acid or benzoic acid as immediate precursors of SA. It is unknown which pathway is (primarily) used by elm for biosynthesis of SA. If SA is generated in elm primarily via the PAL pathway, it would seem to be less sensitive to egg deposition alone than the IC pathway, since neither $P A L$ expression nor $\mathrm{SA}$ levels in elm change in response to egg deposition per se. In A. thaliana, SA levels are known to increase in response to $P$. brassicae egg deposition (Hilfiker et al. 2014; Bonnet et al. 2017; Gouhier-Darimont et al. 2019; Lortzing et al. 2019). Furthermore, A. thaliana SID2, which encodes isochorismate synthase 1 , was found to be significantly induced by insect egg deposition alone (Valsamakis et al. 2020), thus suggesting a sensitivity in the IC pathway to insect eggs. 
An increase in SA levels is usually thought to antagonise JA-regulated plant defensive responses (e.g., Koornneef and Pieterse 2008; Thaler et al. 2012). However, Austel et al. (2016) showed that elm defences against elm leaf beetle larvae were more efficient when leaves had received the beetle's eggs prior to larval feeding damage. There is increasing evidence that the relationship between SA and JA is more complex than simple antagonism, with neutral and coordinated effects occurring too, often depending on the magnitude and timing of induction (Schenk et al. 2000; Mur et al. 2006; Salas-Marina et al. 2011; Rostás et al. 2013; Liu et al. 2016).

\section{Effects of egg deposition and larval feeding on elm genes involved in the phenylpropanoid pathway}

PAL is required for the production of phenylalanine-derived compounds, which are involved in anti-herbivore defences in numerous plant species (War et al. 2018). Several abiotic and biotic cues, including wounding and insect feeding damage, are well known for inducing upregulation of $P A L$ gene expression and enzyme activity (Hartley and Firn 1989; Major and Constabel 2006; Ralph et al. 2006; Dreischhoff et al. 2020). PAL is also known to be induced 3 days after insect egg deposition upon A. thaliana (Little et al. 2007). Furthermore, expression of $P A L$ is inducible in elm by fungi causing Dutch elm disease (Martín et al. 2019 and references therein). PAL expression is not only inducible, but also primable, in wounded or phytopathogen-infected leaves by a pre-treatment with SA or with benzothiadiazole (BTH), a synthetic SA analogue (Kohler et al. 2002; Conrath et al. 2006, and references therein). However, until the present study, the primability of $P A L$ expression in feeding-induced leaves due to an infestation-indicating cue, i.e., insect egg deposition, has not been investigated.

While feeding-induced $P A L$ expression was enhanced by prior egg deposition upon elm leaves, no such egg-mediated effects were detected for the expression of other genes of the phenylpropanoid pathway. Larval feeding induced expression of elm sequences homologous to leucoanthocyanidin dioxygenase $(A N S)$ and shikimate $O$-hydroxycinnamoyltransferase $(H C T)$ independent of prior egg deposition in both EF and F leaves. In contrast, expression of a HCT homologue in the bittersweet nightshade $S$. dulcamara was even downregulated in egg-free leaves damaged by Spodoptera exigua larval feeding, while transcript levels in previously egg-laden, feeding-damaged leaves were upregulated (Geuss et al. 2018); these findings indicate that HCT responses to feeding damage and egg deposition are specific to the plant-insect interaction in question.

None of the other genes studied here were expressed differently in response to larval feeding and/or egg deposition. That larval feeding did not induce these genes is surprising, since several genes downstream of $P A L$ in the phenylpropanoid pathway are known to be inducible by wounding or insect feeding (e.g., 4CL: Soltani et al. 2006; CAD: Barakat et al. 2010; $F 3^{\prime} H$ : Onkokesung et al. 2014). It could be that the damage inflicted by neonate larvae feeding for $24 \mathrm{~h}$ upon the elm leaves was too minimal to induce transcription of these genes. Another possibility is that we might have analysed isoforms of these genes which are not inducible by wounding; for example, two isoforms of $4 C L$ in A. thaliana have been shown to be wound-inducible, but a third one did not respond to wounding (Ehlting et al. 1999).

\section{Effects of egg deposition and larval feeding on elm flavonoid levels}

Neither egg deposition nor feeding damage alone changed levels of elm leaf flavonoids. However, the flavonol core structures, kaempferol and quercetin, were produced in significantly higher concentrations in egg-treated, feeding-damaged elm leaves than in untreated controls. Similarly, total levels of quercetin and kaempferol derivatives were significantly higher in egg-treated, feeding-damaged A. thaliana leaves when compared to untreated controls and to egg-free, feeding-damaged leaves (Lortzing et al. 2019). Egg-treated, feeding-damaged tobacco plants ( $N$. attenuata) have also shown significantly higher levels of a certain phenylpropanoid, caffeoylputrescine, than egg-free, damaged leaves, while egg deposition alone did not induce this phenylpropanoid (Bandoly et al. 2015). Hence, while the response of plants to insect egg deposition alone varies with the specific plant and insect species, in all interactions studied so far, the concentrations of phenylpropanoids were higher when egg deposition preceded larval feeding.

The changes of elm metabolite concentrations in response to the study treatments hardly matched the changes in expression of genes involved in their biosynthesis. We expected the enhanced levels of kaempferol and quercetin in EF leaves to be accompanied by enhanced transcript levels of $F L S / F 3 H$ and $F 3^{\prime} H$, the genes involved in biosynthesis of these compounds. However, this was not the case. Likewise, Schulz et al. (2015) and Pastore et al. (2017) discovered only weak correlations between temperature-induced transcript and metabolite levels of flavonoids. We suggest that in elm increased levels of basic precursors of flavonol biosynthesis are provided by the egg-mediated, feedinginduced potentiation of $P A L$ expression. However, since biosynthesis of phenylpropanoids is not exclusively regulated transcriptionally (Deng and Lu 2017; Yu et al. 2019; Sharma et al. 2019; Nabavi et al. 2020), it could be that posttranscriptional or post-translational mechanisms affected the production of kaempferol and quercetin in elm EF leaves. A previous RNA-seq analysis showed earlier and/or faster 
transcriptional regulation in elm EF than in $\mathrm{F}$ leaves after the onset of larval feeding; interestingly, a gene ontology term enrichment analysis indicated that among these early responding transcripts in EF leaves is a set of transcripts with a function in post-translational protein modification (Altmann et al. 2018). Future studies will need to investigate whether post-translational processes regulate flavonoid biogenesis in response to elm leaf beetle infestation.

Although it has been shown that a high concentration of a kaempferol glycoside causes increased mortality of elm leaf beetle larvae (Austel et al. 2016), the mode of action of flavonols on elm leaf beetle larvae is unknown. An early elm response at the onset of feeding by neonate larvae may be an efficient defence trait because young larvae may be especially sensitive to defensive phytochemicals (Zalucki et al. 2002).

\section{Concluding remarks}

Our study has demonstrated that a tree species, U. minor, responds to the combination of insect egg deposition and feeding by enhancing $P A L$ transcript levels, concentrations of SA, and the flavonols kaempferol and quercetin. When comparing elm responses to insect eggs and larval feeding with those of other plant species, no response pattern typical for perennial versus annual plant species was found. However, from an ecological perspective, the plant species studied here and elsewhere show similarly improved defences against larval feeding damage after having received egg depositions.

Differences between plant species' phytohormonal, transcriptional and metabolic responses to insect eggs and larval feeding may not only be due to species-specific sensitivity to insect eggs, but also to species-specific kinetics of responses, meaning the time points used for taking measurements are crucial. Using the elm leaf sampling time points here, we did not detect effects of egg deposition alone on phytohormone levels, gene expression or metabolite levels. However, a previous study by Altmann et al. (2018) demonstrated that a few hundred elm genes show moderate differential expression very early on, i.e., $1 \mathrm{~h}$ after egg deposition; this early response to eggs was short-lived and later returned to control levels. Our metabolite study here indicates that this very early differential gene expression in response to elm leaf beetle eggs does not result in sustainable accumulation of phenylpropanoids or enhanced levels of phytohormones, which are maintained until later time points. Further studies need to address the question of how the elm's response to eggs can potentiate the response to larval feeding damage, and in doing so will need to consider the impact of, for instance, egg-mediated epigenetic and chromatin-based modifications or small RNAs, which are known to regulate the priming of responses to stress in annual plant species (Rasmann et al. 2012; Lämke and Bäurle 2017; Hilker and Schmülling 2019).

Author contribution statement JS and BF performed and evaluated all experiments and analyses other than the LCMS analyses, which were conducted by $\mathrm{CB}$ and evaluated by JS, BF and CB. MH conceptualised, designed and organised the study. JS and BF wrote a first draft of the manuscript, MH significantly contributed to a later draft, and all authors contributed to, and agreed upon, the final version.

Supplementary Information The online version contains supplementary material available at https://doi.org/10.1007/s00425-021-03803-0.

Acknowledgements We wish to thank the Collaborative Research Centre 973 ("Priming and Memory of Organismic Responses to Stress"), funded by the German Research Foundation (DFG), for financial support. Furthermore, we gratefully acknowledge the technical assistance of Gabriele Haberberger and Jona Höfflin, Freie Universität (FU) Berlin, in insect rearing and plant growing. We would also like to thank Andreas Springer, BioSupraMol at FU Berlin, and Tobias Lortzing, University Hohenheim, for their support in analysing the phytohormone concentrations. Many thanks are due to Didier Morin for collecting elm leaf beetles in the field, and to all of our student helpers for maintaining a laboratory colony of the field-collected beetles.

Funding Open Access funding enabled and organized by Projekt DEAL. This article was funded by Deutsche Forschungsgemeinschaft (Grant No: SFB973).

Data availability The data supporting the findings of this study are available in the main text and online, in the Supplementary Data.

\section{Declarations}

Conflict of interest The authors have no conflict of interest to declare.

Open Access This article is licensed under a Creative Commons Attribution 4.0 International License, which permits use, sharing, adaptation, distribution and reproduction in any medium or format, as long as you give appropriate credit to the original author(s) and the source, provide a link to the Creative Commons licence, and indicate if changes were made. The images or other third party material in this article are included in the article's Creative Commons licence, unless indicated otherwise in a credit line to the material. If material is not included in the article's Creative Commons licence and your intended use is not permitted by statutory regulation or exceeds the permitted use, you will need to obtain permission directly from the copyright holder. To view a copy of this licence, visit http://creativecommons.org/licenses/by/4.0/.

\section{References}

Altmann S, Muino JM, Lortzing V, Brandt R, Himmelbach A, Altschmied L, Hilker M (2018) Transcriptomic basis for reinforcement of elm antiherbivore defence mediated by insect egg 
deposition. Mol Ecol 27:4901-4915. https://doi.org/10.1111/mec. 14900

Austel N, Eilers EJ, Meiners T, Hilker M (2016) Elm leaves 'warned' by insect egg deposition reduce survival of hatching larvae by a shift in their quantitative leaf metabolite pattern. Plant Cell Environ 39:366-376. https://doi.org/10.1111/pce.12619

Bandoly M, Hilker M, Steppuhn A (2015) Oviposition by Spodoptera exigua on Nicotiana attenuata primes induced plant defence against larval herbivory. Plant J 83:661-672. https://doi.org/10. $1111 /$ tpj. 12918

Barakat A, Bagniewska-Zadworna A, Frost CJ, Carlson JE (2010) Phylogeny and expression profiling of $C A D$ and $C A D$-like genes in hybrid Populus (P. deltoides $\times$ P. nigra): evidence from herbivore damage for subfunctionalization and functional divergence. BMC Plant Biol 10:100. https://doi.org/10.1186/1471-2229-10-100

Bate-Smith EC, Richens RH (1973) Flavonoid chemistry and taxonomy in Ulmus. Biochem Syst Ecol 1:141-146. https://doi.org/10.1016/ 0305-1978(73)90004-5

Beyaert I, Köpke D, Stiller J, Hammerbacher A, Yoneya K, Schmidt A, Gershenzon J, Hilker M (2012) Can insect egg deposition 'warn' a plant of future feeding damage by herbivorous larvae? Proc Biol Sci 279:101-108. https://doi.org/10.1098/rspb.2011.0468

Boeckler GA, Gershenzon J, Unsicker SB (2011) Phenolic glycosides of the Salicaceae and their role as anti-herbivore defenses. Phytochemistry 72:1497-1509. https://doi.org/10.1016/j.phytochem. 2011.01.038

Bonnet C, Lassueur S, Ponzio C, Gols R, Dicke M, Reymond P (2017) Combined biotic stresses trigger similar transcriptomic responses but contrasting resistance against a chewing herbivore in Brassica nigra. BMC Plant Biol 17:127. https://doi.org/10.1186/ s12870-017-1074-7

Boyd IL, Freer-Smith PH, Gilligan CA, Godfray HCJ (2013) The consequence of tree pests and diseases for ecosystem services. Science 342:1235773. https://doi.org/10.1126/science.1235773

Büchel K, Fenning T, Gershenzon J, Hilker M, Meiners T (2016) Elm defence against herbivores and pathogens: morphological, chemical and molecular regulation aspects. Phytochem Rev 15:961-983. https://doi.org/10.1007/s11101-015-9442-0

Caldwell E, Read J, Sanson GD (2016) Which leaf mechanical traits correlate with insect herbivory among feeding guilds? Ann Bot 117:349-361. https://doi.org/10.1093/aob/mcv178

Conrath U, Beckers GJM, Flors V et al (2006) Priming: getting ready for battle. Mol Plant Microbe Interact 19:1062-1071. https://doi. org/10.1094/MPMI-19-1062

Conrath U, Beckers GJM, Langenbach CJG, Jaskiewicz MR (2015) Priming for enhanced defence. Annu Rev Phytopathol 53:97-119. https://doi.org/10.1146/annurev-phyto-080614-120132

Dempsey DA, Vlot AC, Wildermuth MC, Klessig DF (2011) Salicylic acid biosynthesis and metabolism. Arabidopsis Book. https://doi. org/10.1199/tab.0156

Deng Y, Lu S (2017) Biosynthesis and regulation of phenylpropanoids in plants. Crit Rev Plant Sci 36:257-290. https://doi.org/10.1080/ 07352689.2017.1402852

Dreischhoff S, Das IS, Jakobi M, Kasper K, Polle A (2020) Local responses and systemic induced resistance mediated by ectomycorrhizal fungi. Front Plant Sci 11:590063. https://doi.org/10.3389/ fpls.2020.590063

Drok S, Bandoly M, Stelzer S, Lortzing T, Steppuhn A (2018) Moth oviposition shapes the species-specific transcriptional and phytohormonal response of Nicotiana attenuata to larval feeding. Sci Rep 8:10249. https://doi.org/10.1038/s41598-018-28233-z

Ehlting J, Büttner D, Wang Q, Douglas CJ, Somssich IE, Kombrink E (1999) Three 4-coumarate:coenzyme A ligases in Arabidopsis thaliana represent two evolutionarily divergent classes in angiosperms. Plant J 19:9-20. https://doi.org/10.1046/j.1365-313x. 1999.00491.x
Farmer EE, Gao Y-Q, Lenzoni G, Wolfender J-L, Wu Q (2020) Wound- and mechanostimulated electrical signals control hormone responses. New Phytol 227:1037-1050. https://doi.org/10. $1111 / n$ ph. 16646

Fox J, Weisberg S (2018) An R companion to applied regression. SAGE Publications, London

Frost CJ, Mescher MC, Carlson JE, Moraes CMD (2008) Plant defense priming against herbivores: getting ready for a different battle. Plant Physiol 146:818-824. https://doi.org/10.1104/pp.107. 113027

Geuss D, Lortzing T, Schwachtje J, Kopka J, Steppuhn A (2018) Oviposition by Spodoptera exigua on Solanum dulcamara alters the plant's response to herbivory and impairs larval performance. Int J Mol Sci 19:4008. https://doi.org/10.3390/ijms19124008

Gouhier-Darimont C, Stahl E, Glauser G, Reymond P (2019) The Arabidopsis lectin receptor kinase LecRK-I.8 is involved in insect egg perception. Front Plant Sci 10:623. https://doi.org/10.3389/ fpls.2019.00623

Gu Z, Eils R, Schlesner M (2016) Complex heatmaps reveal patterns and correlations in multidimensional genomic data. Bioinformatics 32:2847-2849. https://doi.org/10.1093/bioinformatics/btw313

Hartley SE, Firn RD (1989) Phenolic biosynthesis, leaf damage, and insect herbivory in birch (Betula pendula). J Chem Ecol 15:275283. https://doi.org/10.1007/BF02027789

Haukioja E (1991) Induction of defenses in trees. Annu Rev Entomol 36:25-42. https://doi.org/10.1146/annurev.en.36.010191.000325

Hertog MGL, Hollman PCH, Katan MB (1992) Content of potentially anticarcinogenic flavonoids of 28 vegetables and 9 fruits commonly consumed in the Netherlands. J Agric Food Chem 40:2379-2383. https://doi.org/10.1021/jf00024a011

Hilfiker O, Groux R, Bruessow F, Kiefer K, Zeier J, Reymond P (2014) Insect eggs induce a systemic acquired resistance in Arabidopsis. Plant J 80:1085-1094. https://doi.org/10.1111/ tpj. 12707

Hilker M, Fatouros NE (2016) Resisting the onset of herbivore attack: plants perceive and respond to insect eggs. Curr Opin Plant Biol 32:9-16. https://doi.org/10.1016/j.pbi.2016.05.003

Hilker M, Schmülling T (2019) Stress priming, memory, and signalling in plants. Plant Cell Environ 42:753-761. https://doi.org/10. 1111/pce.13526

Hilker M, Schwachtje J, Baier M et al (2016) Priming and memory of stress responses in organisms lacking a nervous system. Biol Rev 91:1118-1133. https://doi.org/10.1111/brv.12215

Hothorn T, Bretz F, Westfall P (2008) Simultaneous inference in general parametric models. Biom J 50:346-363. https://doi.org/10. 1002/bimj.200810425

Ikoma Y, Yano M, Ogawa K, Yoshioka T, Xu ZC, Hisada S, Omura M, Moriguchi T (1996) Isolation and evaluation of RNA from polysaccharide-rich tissues in fruit for quality by cDNA library construction and RT-PCR. J Jpn Soc Hortic Sci 64:809-814. https://doi.org/10.2503/jjshs.64.809

Karban R (2011) The ecology and evolution of induced resistance against herbivores. Funct Ecol 25:339-347. https://doi.org/10. 1111/j.1365-2435.2010.01789.x

Kim J, Tooker JF, Luthe DS, Moraes CMD, Felton GW (2012) Insect eggs can enhance wound response in plants: a study system of tomato Solanum lycopersicum L. and Helicoverpa zea Boddie. PLoS One 7:e37420. https://doi.org/10.1371/journal.pone.00374 20

Kohler A, Schwindling S, Conrath U (2002) Benzothiadiazole-induced priming for potentiated responses to pathogen infection, wounding, and infiltration of water into leaves requires the NPRI/NIMI gene in Arabidopsis. Plant Physiol 128:1046-1056. https://doi. org/10.1104/pp.010744 
Koornneef A, Pieterse CMJ (2008) Cross talk in defense signaling. Plant Physiol 146:839-844. https://doi.org/10.1104/pp.107. 112029

Lämke J, Bäurle I (2017) Epigenetic and chromatin-based mechanisms in environmental stress adaptation and stress memory in plants. Genome Biol 18:124. https://doi.org/10.1186/s13059-017-1263-6

Li T, Blande JD (2017) Volatile-mediated within-plant signaling in hybrid aspen: required for systemic responses. J Chem Ecol 43:327-338. https://doi.org/10.1007/s10886-017-0826-z

Little D, Gouhier-Darimont C, Bruessow F, Reymond P (2007) Oviposition by pierid butterflies triggers defense responses in Arabidopsis. Plant Physiol 143:784-800. https://doi.org/10.1104/pp. 106.090837

Liu L, Sonbol F-M, Huot B, Gu Y, Withers J, Mwimba M, Yao J, He SY, Dong X (2016) Salicylic acid receptors activate jasmonic acid signalling through a non-canonical pathway to promote effectortriggered immunity. Nat Commun 7:13099. https://doi.org/10. 1038/ncomms 13099

Livak KJ, Schmittgen TD (2001) Analysis of relative gene expression data using real-time quantitative PCR and the $2^{-\Delta \Delta C T}$ method. Methods 25:402-408. https://doi.org/10.1006/meth.2001.1262

Lortzing V, Oberländer J, Lortzing T, Tohge T, Steppuhn A, Kunze R, Hilker M (2019) Insect egg deposition renders plant defence against hatching larvae more effective in a salicylic acid-dependent manner. Plant Cell Environ 42:1019-1032. https://doi.org/ $10.1111 /$ pce. 13447

Major IT, Constabel CP (2006) Molecular analysis of poplar defense against herbivory: comparison of wound- and insect elicitorinduced gene expression. New Phytol 172:617-635. https://doi. org/10.1111/j.1469-8137.2006.01877.x

Martín JA, Witzell J, Blumenstein K, Rozpedowska E, Helander M, Sieber TN, Gil L (2013) Resistance to Dutch elm disease reduces presence of xylem endophytic fungi in elms (Ulmus spp.). PLoS One 8:e56987. https://doi.org/10.1371/journal.pone.00569 87

Martín JA, Sobrina-Plata J, Rodriguez-Calcerrada J, Collada C, Gil L (2019) Breeding and scientific advances in the fight against Dutch elm disease: will they allow the use of elms in forest restoration? New For 50:183-215. https://doi.org/10.1007/s11056-018-9640-x

Mattila P, Astola J, Kumpulainen J (2000) Determination of flavonoids in plant material by HPLC with diode-array and electroarray detections. J Agric Food Chem 48:5834-5841. https://doi. org/10.1021/jf000661f

Mauch-Mani B, Baccelli I, Luna E, Flors V (2017) Defense priming: an adaptive part of induced resistance. Annu Rev Plant Biol 68:485512. https://doi.org/10.1146/annurev-arplant-042916-041132

Meiners T, Hilker M (2000) Induction of plant synomones by oviposition of a phytophagous insect. J Chem Ecol 26:221-232. https:// doi.org/10.1023/A:1005453830961

Mur LAJ, Kenton P, Atzorn R, Miersch O, Wasternack C (2006) The outcomes of concentration-specific interactions between salicylate and jasmonate signaling include synergy, antagonism, and oxidative stress leading to cell death. Plant Physiol 140:249-262. https://doi.org/10.1104/pp.105.072348

Nabavi SM, Šamec D, Tomczyk M et al (2020) Flavonoid biosynthetic pathways in plants: versatile targets for metabolic engineering. Biotechnol Adv 38:107316. https://doi.org/10.1016/j.biotechadv. 2018.11.005

Onkokesung N, Reichelt M, van Doorn A, Schuurink RC, van Loon JJA, Dicke M (2014) Modulation of flavonoid metabolites in Arabidopsis thaliana through overexpression of the MYB75 transcription factor: role of kaempferol-3,7-dirhamnoside in resistance to the specialist insect herbivore Pieris brassicae. J Exp Bot 65:2203-2217. https://doi.org/10.1093/jxb/eru096

Pastore C, Dal Santo S, Zenoni S, Movahed N, Allegro G, Valentini G, Filippetti I, Tornielli GB (2017) Whole plant temperature manipulation affects flavonoid metabolism and the transcriptome of grapevine berries. Front Plant Sci 8:929. https://doi.org/10. 3389/fpls.2017.00929

Perdiguero P, Venturas M, Cervera MT, Gil L, Collada C (2015) Massive sequencing of Ulmus minor's transcriptome provides new molecular tools for a genus under the constant threat of Dutch elm disease. Front Plant Sci 6:1-12. https://doi.org/10.3389/fpls. 2015.00541

R Core Team (2020) R: a language and environment for statistical computing. R Foundation for Statistical Computing, Vienna

Ralph S, Oddy C, Cooper D et al (2006) Genomics of hybrid poplar (Populus trichocarpax deltoides) interacting with forest tent caterpillars (Malacosoma disstria): normalized and full-length cDNA libraries, expressed sequence tags, and a cDNA microarray for the study of insect-induced defences in poplar. Mol Ecol 15:1275-1297. https://doi.org/10.1111/j.1365-294X.2006. 02824.x

Rasmann S, Vos MD, Casteel CL, Tian D, Halitschke R, Sun JY, Agrawal AA, Felton GW, Jander G (2012) Herbivory in the previous generation primes plants for enhanced insect resistance. Plant Physiol 158:854-863. https://doi.org/10.1104/pp.111.187831

Rekhter D, Lüdke D, Ding Y, Feussner K, Zienkiewicz K, Lipka V, Wiermer M, Zhang Y, Feussner I (2019) Isochorismate-derived biosynthesis of the plant stress hormone salicylic acid. Science 365:498-502. https://doi.org/10.1126/science.aaw1720

Reymond P (2013) Perception, signaling and molecular basis of oviposition-mediated plant responses. Planta 238:247-258. https:// doi.org/10.1007/s00425-013-1908-y

Rostás M, Winter TR, Borkowski L, Zeier J (2013) Copper and herbivory lead to priming and synergism in phytohormones and plant volatiles in the absence of salicylate-jasmonate antagonism. Plant Signal Behav 8:e24264. https://doi.org/10.4161/psb.24264

Salas-Marina MA, Silva-Flores MA, Uresti-Rivera EE, Castro-Longoria E, Herrera-Estrella A, Casas-Flores S (2011) Colonization of Arabidopsis roots by Trichoderma atroviride promotes growth and enhances systemic disease resistance through jasmonic acid/ethylene and salicylic acid pathways. Eur J Plant Pathol 131:15-26. https://doi.org/10.1007/s10658-011-9782-6

Santamour FS (1972) Flavonoid distribution in Ulmus. Bull Torrey Bot Club 99:127-131. https://doi.org/10.2307/2484692

Schenk PM, Kazan K, Wilson I, Anderson JP, Richmond T, Somerville SC, Manners JM (2000) Coordinated plant defense responses in Arabidopsis revealed by microarray analysis. Proc Natl Acad Sci USA 97:11655-11660. https://doi.org/10.1073/pnas.97.21.11655

Schulz E, Tohge T, Zuther E, Fernie AR, Hincha DK (2015) Natural variation in flavonol and anthocyanin metabolism during cold acclimation in Arabidopsis thaliana accessions. Plant Cell Environ 38:1658-1672. https://doi.org/10.1111/pce.12518

Sharma A, Shahzad B, Rehman A, Bhardwaj R, Landi M, Zheng B (2019) Response of phenylpropanoid pathway and the role of polyphenols in plants under abiotic stress. Molecules 24:2452. https://doi.org/10.3390/molecules24132452

Smith CA, Want EJ, O'Maille G, Abagyan R, Siuzdak G (2006) XCMS: processing mass spectrometry data for metabolite profiling using nonlinear peak alignment, matching, and identification. Anal Chem 78:779-787. https://doi.org/10.1021/ac051437y

Soltani BM, Ehlting J, Hamberger B, Douglas CJ (2006) Multiple cis-regulatory elements regulate distinct and complex patterns of developmental and wound-induced expression of Arabidopsis thaliana 4CL gene family members. Planta 224:1226-1238. https://doi.org/10.1007/s00425-006-0296-y

Stam JM, Kroes A, Li Y, Gols R, van Loon JJA, Poelman EH, Dicke M (2014) Plant interactions with multiple insect herbivores: from community to genes. Annu Rev Plant Biol 65:689-713. https:// doi.org/10.1146/annurev-arplant-050213-035937 
Thaler JS, Humphrey PT, Whiteman NK (2012) Evolution of jasmonate and salicylate signal crosstalk. Trends Plant Sci 17:260-270. https://doi.org/10.1016/j.tplants.2012.02.010

Tohge T, de Souza LP, Fernie AR (2017) Current understanding of the pathways of flavonoid biosynthesis in model and crop plants. J Exp Bot 68:4013-4028. https://doi.org/10.1093/jxb/erx177

Tscharntke T, Thiessen S, Dolch R, Boland W (2001) Herbivory, induced resistance, and interplant signal transfer in Alnus glutinosa. Biochem Syst Ecol 29:1025-1047. https://doi.org/10.1016/ S0305-1978(01)00048-5

Turlings TCJ, Erb M (2018) Tritrophic interactions mediated by herbivore-induced plant volatiles: mechanisms, ecological relevance, and application potential. Annu Rev Entomol 63:433-452. https:// doi.org/10.1146/annurev-ento-020117-043507

Valsamakis G, Bittner N, Fatouros NE, Kunze R, Hilker M, Lortzing V (2020) Priming by timing: Arabidopsis thaliana adjusts its priming response to Lepidoptera eggs to the time of larval hatching. Front Plant Sci 11:619589. https://doi.org/10.3389/fpls. 2020.619589

Vandesompele J, De Preter K, Pattyn F, Poppe B, Van Roy N, De Paepe A, Speleman F (2002) Accurate normalization of real-time quantitative RT-PCR data by geometric averaging of multiple internal control genes. Genome Biol 3:research0034.1. https://doi.org/10. 1186/gb-2002-3-7-research0034

Vogt T (2010) Phenylpropanoid biosynthesis. Mol Plant 3:2-20. https:// doi.org/10.1093/mp/ssp106

Wang L, Halitschke R, Kang J-H, Berg A, Harnisch F, Baldwin IT (2007) Independently silencing two JAR family members impairs levels of trypsin proteinase inhibitors but not nicotine. Planta 226:159-167. https://doi.org/10.1007/s00425-007-0477-3

War AR, Taggar GK, Hussain B, Taggar MS, Nair RM, Sharma HC (2018) Plant defence against herbivory and insect adaptations. AoB Plants 10:ply037. https://doi.org/10.1093/aobpla/ply037
Wickham H (2011) The split-apply-combine strategy for data analysis. J Stat Softw 40:1-29. https://doi.org/10.18637/jss.v040.i01

Wickham H (2016) ggplot2: Elegant graphics for data analysis, 2nd edn. Springer International Publishing, Basel

Wilkinson SW, Magerøy MH, López Sánchez A, Smith LM, Furci L, Cotton TEA, Krokene P, Ton J (2019) Surviving in a hostile world: plant strategies to resist pests and diseases. Annu Rev Phytopathol 57:505-529. https://doi.org/10.1146/annur ev-phyto-082718-095959

Wu J, Baldwin IT (2010) New insights into plant responses to the attack from insect herbivores. Annu Rev Genet 44:1-24. https:// doi.org/10.1146/annurev-genet-102209-163500

Yu S, Kim H, Yun D-J, Suh MC, Lee B (2019) Post-translational and transcriptional regulation of phenylpropanoid biosynthesis pathway by Kelch repeat F-box protein SAGL1. Plant Mol Biol 99:135-148. https://doi.org/10.1007/s11103-018-0808-8

Zalucki MP, Clarke AR, Malcolm SB (2002) Ecology and behavior of first instar larval Lepidoptera. Annu Rev Entomol 47:361-393. https://doi.org/10.1146/annurev.ento.47.091201.145220

Zhang X, Liu C-J (2015) Multifaceted regulations of gateway enzyme phenylalanine ammonia-lyase in the biosynthesis of phenylpropanoids. Mol Plant 8:17-27. https://doi.org/10.1016/j.molp.2014. 11.001

Publisher's Note Springer Nature remains neutral with regard to jurisdictional claims in published maps and institutional affiliations. 